\title{
Calorimetry in the near-critical and supercritical regions. Nitrous oxide + hydrocarbon mixtures*
}

\author{
Juan A. R. Renuncioł, Albertina Cabañas and Concepción Pando \\ Departamento de Química Física I, Universidad Complutense E-28040 Madrid Spain
}

\begin{abstract}
The high pressure calorimeters developed in the last 20 years are briefly reviewed. Most of them have been used to obtain excess enthalpy data $\left(\mathrm{H}_{\mathrm{m}}^{\mathrm{E}}\right)$ in the critical and supercritical regions. Data are available for many mixtures formed by carbon dioxide and for a few involving other supercritical fluids such as ethane, methane, nitrous oxide, etc. Data for several $\mathrm{N}_{2} \mathrm{O}$ + hydrocarbon mixtures were recently measured from 308.15 to $323.15 \mathrm{~K}$ and from 7.64 to $15.00 \mathrm{MPa}$. Excess enthalpies for $\mathrm{N}_{2} \mathrm{O}$ + hydrocarbon mixtures were calculated using several cubic equations of state (EOS). Two noncubic EOS which combine the Carnahan-Starling hard-sphere term with the van der Waals and Redlich-Kwong attractive terms, were also used. The classical van der Waals mixing rules and those proposed by Wong and Sandler were used. The ability of the cubic EOS to correlate the excess enthalpies of the $\mathrm{N}_{2} \mathrm{O}$ + hydrocarbon mixtures seems to be related to the proximity of conditions of temperature and pressure to the $\mathrm{N}_{2} \mathrm{O}$ critical point.
\end{abstract}

\section{CALORIMETRY IN THE CRITICAL REGION}

The increasing interest in supercritical fluids runs parallel with the increasing use of calorimetry in the near-critical and supercritical regions. The aim is to study the energetic interactions of molecules under these particular conditions. During the last two decades, high pressure calorimetry has shifted almost completely to supercritical fluid applications. The first experimental device to measure the endothermic excess enthalpies of simple mixtures such as $\mathrm{CH}_{4}+\mathrm{N}_{2}, \mathrm{CH}_{4}+\mathrm{H}_{2}$ or $\mathrm{CH}_{4}+\mathrm{Ar}$ was developed by Wormald et al. [1,2] in 1976. A new version is able to reach up to $700 \mathrm{~K}$ and $20 \mathrm{MPa}$, and to measure exothermic processes as well [3]. Simultaneously, Christensen et al. [4,5] were setting up a new highpressure flow calorimeter able to detect both exothermic and endothermic processes which was quickly applied to determine the excess enthalpies of $\mathrm{CO}_{2}+$ hydrocarbon mixtures in the critical region. From 1983 to his early dead, James J. Christensen published data of mixtures such as $\mathrm{CO}_{2}+$ ethane [6], + pentane $[7,8],+$ hexane $[9,10],+$ cyclohexane [11-14], + decane [15,16], + toluene [17-20] and + pyridine $[21,22]$. Figure 1 shows the experimental P,T conditions at which data are available for three of these systems. It may be seen that several types of mixtures-subcritical, supercritical, liquid-were studied. The data showed striking features: highly exothermic or endothermic enthalpies, large temperature and pressure effects, and two-phase linear sections in the $\mathrm{H}_{\mathrm{m}}^{\mathrm{E}} \mathrm{vs}$. composition diagrams. The same equipment has also been used to determine heats of reaction of electrolytes and amino acids. For instance, the heat of reaction of phosphate anions with hydrochloric acid as a function of temperature and pressure was used to determine the protonation constants of phosphate at high temperature [23], and the heat of reaction of amino acids with basic solutions as a function of temperature, pressure and concentration was used to determine, for the first time, the acid disociation constant as a function of temperature $[24,25]$.

Unfortunately, it is not possible to mention all the important contributions in the field. Those

*Lecture presented at the 15th International Conference on Chemical Thermodynamics, Porto, Portugal,

26 July-1 August 1998, pp. 1167-1306.

$\dagger$ Corresponding author: E-mail: renuncio@eucmax.sim.ucm.es 


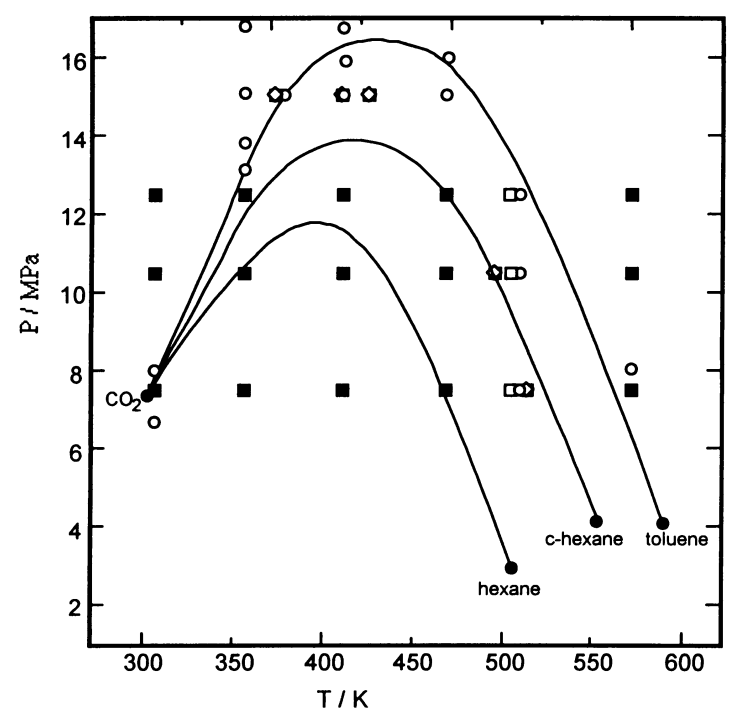

Fig. 1 Plot of $\mathrm{P}$ vs. T showing the temperature-pressure coordinates at which experimental $\mathrm{H}_{\mathrm{m}}^{\mathrm{E}}$ data are available for: $\mathbf{\square}, \mathrm{CO}_{2}+$ toluene, + hexane, and + cyclohexane; $\bigcirc, \mathrm{CO}_{2}+$ toluene; $\square, \mathrm{CO}_{2}+$ hexane; $\diamond, \mathrm{CO}_{2}+$ cyclohexane The critical points of pure compounds $(\bullet)$, and critical loci (-) are also shown.

concerning flow calorimeters were reviewed [26] in 1994. Among the most recent developments, it should be mentioned Grolier et al. [27] modification of a commercial calorimeter. A batch calorimeter was adapted to flow processes using an external device to control the total pressure of the system. This allows to scan the pressure and to determine directly the pressure influence on the thermodynamic variables.

Although there are not well defined standards for high pressure calorimetry, calibration of the equipment is usually carried out using water + ethanol mixtures at temperatures from 298 to $548 \mathrm{~K}$ and pressure from atmospheric to $15 \mathrm{MPa}$. More experimental information is required to establish a reference system at high pressure [28].

The numerous studies of mixtures involving carbon dioxide and hydrocarbons are in contrast with the relatively few studies of mixtures formed by other supercritical fluids acting as solvent of hydrocarbons. During the last years a program is underway at our laboratory to carry out calorimetric experiments of mixtures formed by nitrous oxide + hydrocarbon in the near critical and supercritical regions. Nitrous oxide and carbon dioxide have many similarities in molecular size, mass, critical constants $\left(T_{c}=309.6\right.$ and $304.2 \mathrm{~K}$, respectively; $\mathrm{P}_{\mathrm{c}}=7.24$ and $7.38 \mathrm{MPa}$, respectively), and also some differences in polarity and reactivity. Nevertheless, nitrous oxide is a compound sometimes used in supercritical fluid extraction and several authors [29-31] have reported that $\mathrm{N}_{2} \mathrm{O}$ is a better solvent than $\mathrm{CO}_{2}$ for certain compounds. On the other hand, the explosion risk reported by Sievers \& Hansen [32] seems to be preventing a wider use of supercritical nitrous oxide. For this reason this study is limited to temperatures near the critical point of nitrous oxide.

\section{NITROUS OXIDE + HYDROCARBON MIXTURES}

The experimental $\mathrm{P}, \mathrm{T}$ conditions at which excess enthalpies were determined for mixtures formed by $\mathrm{N}_{2} \mathrm{O}+$ hydrocarbon are plotted in Fig. 2 together with the critical loci of those systems. Critical loci are calculated using the method of Heideman \& Khalil [33]. The experimental $\mathrm{H}_{\mathrm{m}}^{\mathrm{E}}$ data are reported at temperatures ranging from 308.15 to $323.15 \mathrm{~K}$ and pressures from 7.64 to $15.00 \mathrm{MPa}$. These experimental conditions are below and above the critical temperature of $\mathrm{N}_{2} \mathrm{O}$, and above the critical pressure of $\mathrm{N}_{2} \mathrm{O}$. Some of the mixtures are supercritical and all of them are in the critical region of the mixture. Excess molar enthalpies were determined for the $\mathrm{N}_{2} \mathrm{O}$ +hydrocarbon mixtures [34-40] over the entire composition range. Figures 3 and 4 show some typical results obtained. As it may observed in Figs 3, 4 and 5, the excess enthalpy for the $\mathrm{N}_{2} \mathrm{O}+$ hydrocarbon systems change from exothermic to endothermic, 

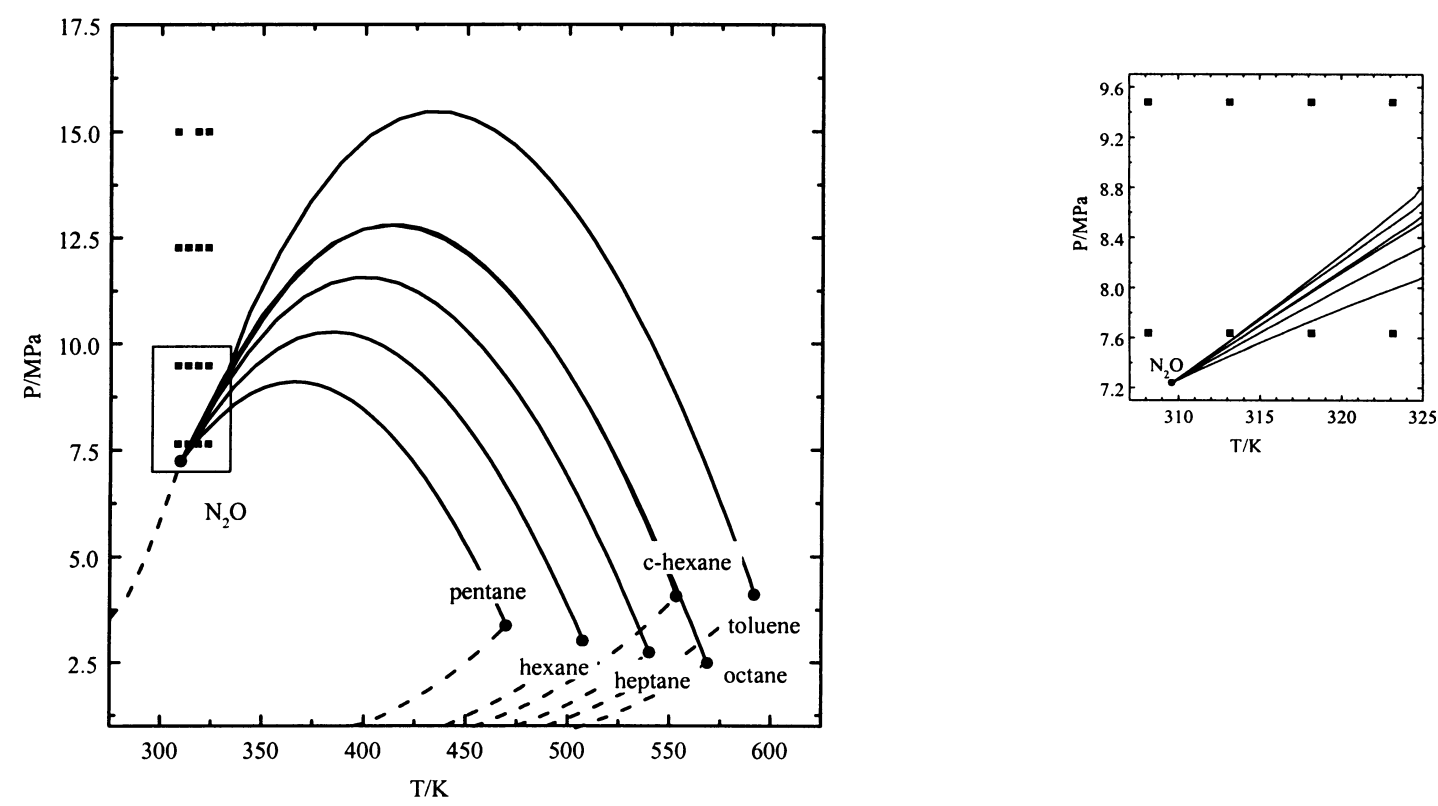

Fig. 2 Plot of $\mathrm{P}$ vs. T showing the temperature-pressure coordinates at which experimental $\mathrm{H}_{\mathrm{m}}^{\mathrm{E}}$ data are available for $\mathrm{N}_{2} \mathrm{O}+$ pentane, + hexane, + heptane, + octane, + cyclohexane, and + toluene, $(\boldsymbol{\square})$, the critical points of pure compounds $(\bullet)$, and critical loci $(-)$.

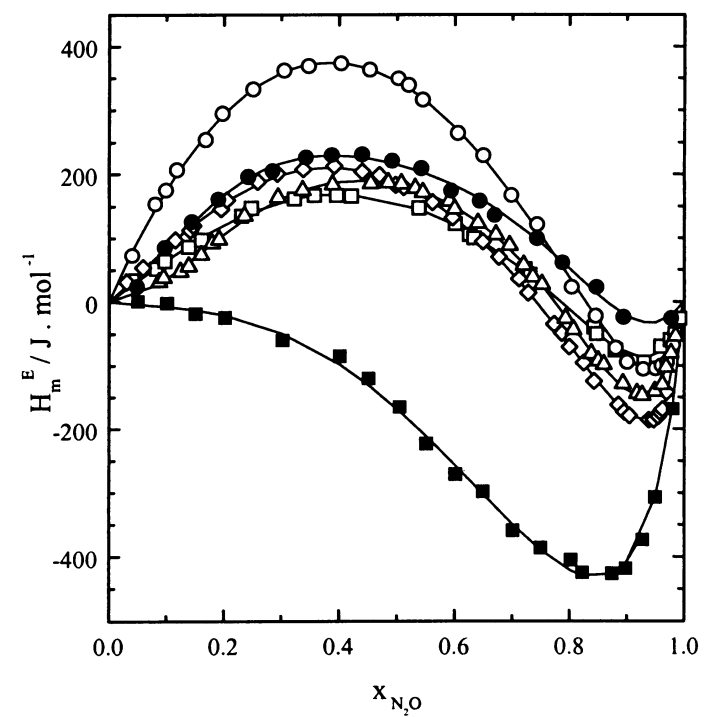

Fig. 3 Excess molar enthalpies vs. $\mathrm{N}_{2} \mathrm{O}$ mole fraction for $\mathrm{N}_{2} \mathrm{O}+$ hydrocarbon at $308.15 \mathrm{~K}$ and 9.48 MPa: $\bigcirc$, cyclohexane; $\square$, hexane; $\triangle$, heptane; $\diamond$, octane; $\bullet$, pentane; $\mathbf{\square}$, toluene, - correlated curve.

or becomes increasingly endothermic, as pressure rises at a given temperature, or becomes less endothermic, as temperature increases at a given pressure. Both, the temperature and pressure effects are large and opposite in sign. The pressure effect is more important at 318.15 and $323.15 \mathrm{~K}$ while the temperature effect is more important at the lower values of pressure. The changes observed in the excess enthalpy with temperature and pressure may be discussed in terms of liquid-vapor equilibrium and critical constants for the $\mathrm{N}_{2} \mathrm{O}$ +hydrocarbon mixtures and the densities of $\mathrm{N}_{2} \mathrm{O}$ and the hydrocarbon at the conditions of temperature and pressure of the experiments.

When the states and densities of the pure components and the mixture are similar, values of $\mathrm{H}_{\mathrm{m}}^{\mathrm{E}}$ are moderately negative or positive. This is so for $\mathrm{N}_{2} \mathrm{O}+$ hydrocarbon for every isobar at $308.15 \mathrm{~K}$ and for 

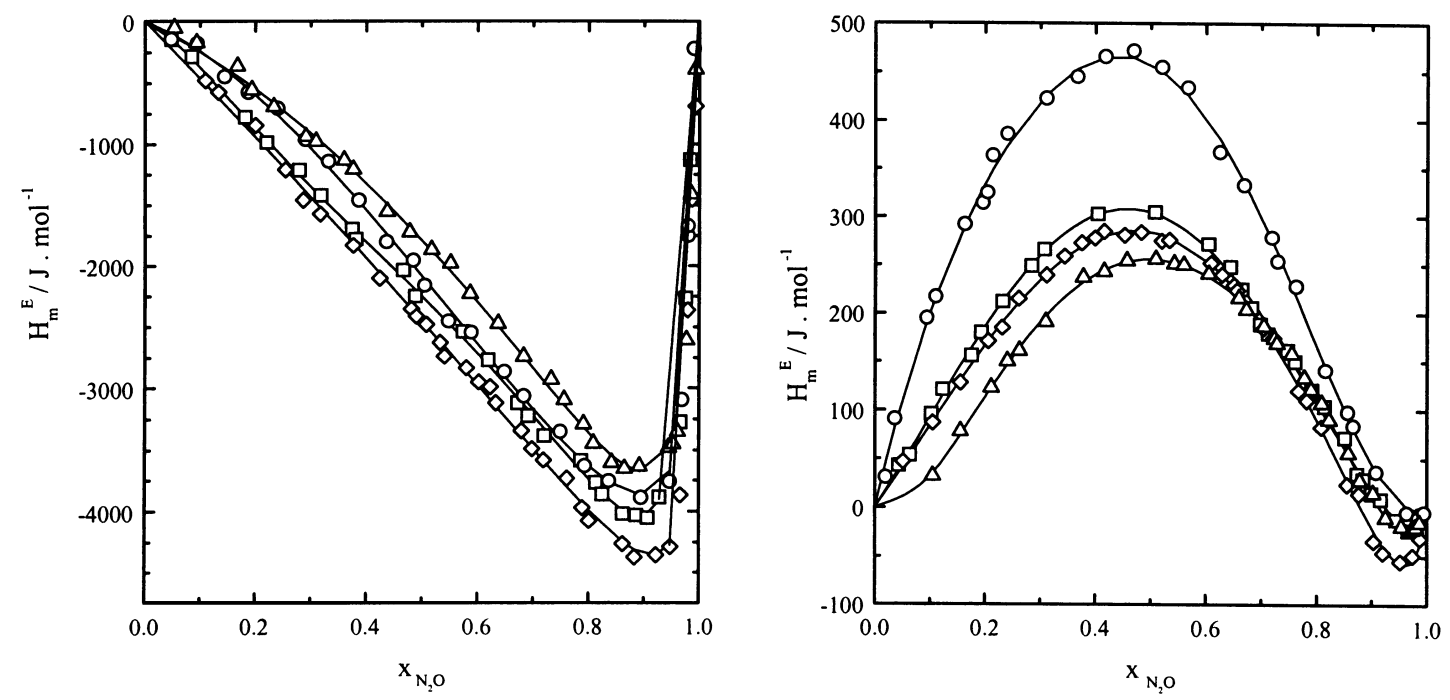

Fig. 4 Excess molar enthalpies vs. $\mathrm{N}_{2} \mathrm{O}$ mole fraction for $\mathrm{N}_{2} \mathrm{O}$ +hydrocarbon at $318.15 \mathrm{~K}$ and $7.64 \mathrm{MPa}$ (left) and 15.00 MPa (right). Symbols are as in Fig. 3.

isobars at 12.27 and $15.00 \mathrm{MPa}$ at $313.15 \mathrm{~K}$ and $318.15 \mathrm{~K}$. When the states and densities of the pure components differ and the resulting mixture is a liquid, large negative values of $\mathrm{H}_{\mathrm{m}}^{\mathrm{E}}$ are observed. This is so for the isobar at $7.64 \mathrm{MPa}$ and temperatures of $313.15,318.15$ and $323.15 \mathrm{~K}$, when a value close to $250 \mathrm{~kg} / \mathrm{m}^{3}$ is obtained for the $\mathrm{N}_{2} \mathrm{O}$ density [41] while values ranging from 645 to $765 \mathrm{~kg} / \mathrm{m}^{3}$ are obtained for the hydrocarbon density, depending on the hydrocarbon. The value of the $\mathrm{N}_{2} \mathrm{O}$ density at these temperatures increases when the pressure goes from 7.60 to $9.48 \mathrm{MPa}$ but it is still considerably lower than that of hydrocarbon. At $9.48 \mathrm{MPa}$, mixtures show moderately endothermic mixing in the hydrocarbon-rich region and very exothermic mixing in the nitrous oxide-rich region. The large negative values of $\mathrm{H}_{\mathrm{m}}^{\mathrm{E}}$ at 318.15 and $323.15 \mathrm{~K}$ and $7.60 \mathrm{MPa}$ seem to be a consequence of the $\mathrm{N}_{2} \mathrm{O}$ change of state from that of a low-density fluid to that of a liquid-mixture component.

The changes observed in the excess enthalpy with temperature and pressure for $\mathrm{N}_{2} \mathrm{O}+$ hydrocarbon are similar to those previously reported for $\mathrm{CO}_{2}+$ hydrocarbon. The critical loci reported for the $\mathrm{CO}_{2}+$ hydrocarbon and those estimated for $\mathrm{N}_{2} \mathrm{O}$ + hydrocarbon are very similar. The critical loci and the $(\mathrm{P}, \mathrm{T})$ dependence of $\mathrm{H}_{\mathrm{m}}^{\mathrm{E}}$ exhibit similar trends for the systems studied. A comparison of the magnitude and position of the minima and maxima appearing in the $\mathrm{H}_{\mathrm{m}}^{\mathrm{E}}$ vs. $\mathrm{x}_{1}$ curves, obtained at a particular condition of $\mathrm{T}$ and $\mathrm{P}$, indicates that results for $\mathrm{N}_{2} \mathrm{O}+$ linear alkane systems are more similar to each other. The magnitude of maxima observed for the $\mathrm{N}_{2} \mathrm{O}$ + cyclohexane is considerably larger than that of maxima for $\mathrm{N}_{2} \mathrm{O}$ + linear alkane. The values for $\mathrm{N}_{2} \mathrm{O}+$ toluene are always more exothermic than those for the other studied systems.

\section{CALCULATION OF THE EXCESS MOLAR ENTHALPY AND PURE COMPONENT PROPERTIES}

The excess molar enthalpy of a binary mixture is calculated as a balance between the residual molar enthalpy of the mixture and those of the pure components, $\mathrm{N}_{2} \mathrm{O}(\mathrm{i}=1)$ and hydrocarbon $(\mathrm{i}=2)$.

$\mathrm{H}_{\mathrm{m}}^{\mathrm{E}}=\left[\mathrm{H}-\mathrm{H}^{*}\right]_{\text {mixture }}-\sum_{\mathrm{i}} \mathrm{x}_{\mathrm{i}}\left[\mathrm{H}-\mathrm{H}^{*}\right]_{\mathrm{i}}$

The residual molar enthalpy is given by

$\mathrm{H}-\mathrm{H}^{*}=\mathrm{R} \cdot \mathrm{T} \cdot(\mathrm{z}-1)+\int_{\infty}^{\mathrm{V}}\left\{\mathrm{T}\left[\frac{\partial \mathrm{P}}{\partial \mathrm{T}}\right]_{\mathrm{V}}-\mathrm{P}\right\} \mathrm{dV}$ 


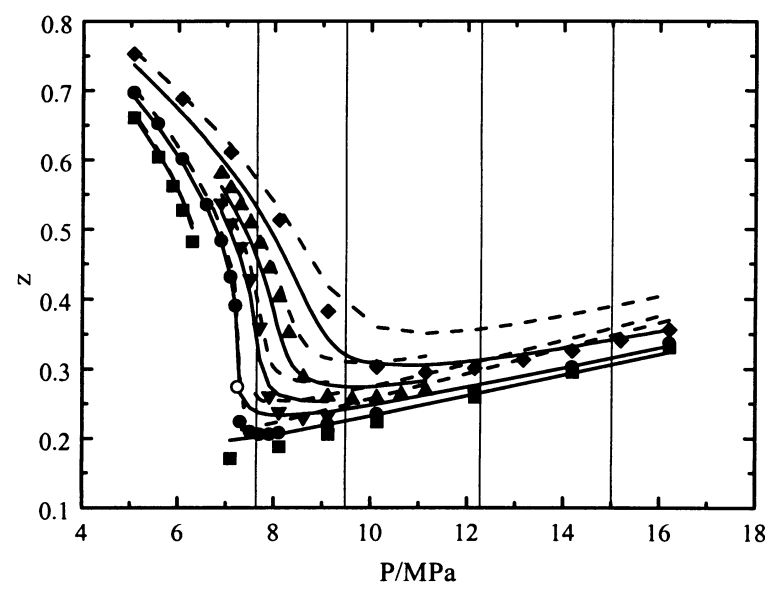

Fig. 5 Experimental and calculated compressibility factor, z, for $\mathrm{N}_{2} \mathrm{O}$ at temperatures near the critical point $(O)$ : $\mathbf{\square}, 303.15 \mathrm{~K} ; \bullet$ •, 309.60 K; $\mathbf{\nabla}, 313.15 \mathrm{~K} ; \boldsymbol{\Delta}, 317.15 \mathrm{~K} ; \diamond, 323.15 \mathrm{~K}$; -, calculated using CSSRK EOS; - - -, calculated using SRK EOS. Vertical lines show the experimental pressures at which $\mathrm{H}_{\mathrm{m}}^{\mathrm{E}}$ are measured in this work.

where $\mathrm{z}$ is the compressibility factor. The equations of state used are:

- Peng-Robinson (PR) EOS [42]—a cubic EOS including two parameters a(T) and b.

- Stryjek \& Vera (PRSV) EOS [43,44]—a modification of the PR EOS introducing a new temperature dependence in parameter $\mathrm{a}(\mathrm{T})$.

- Soave-Redlich-Kwong (SRK) EOS [45]—a cubic EOS including two parameters a(T) and b.

- Patel-Teja (PT) EOS [46] - a cubic EOS including three parameters, a(T), b and c. The critical compressibility factor is considered as an empirical parameter.

- Kubic EOS [47] - a cubic EOS including three parameters, a(T), b and $c(T)$. The temperature dependence of the parameter $\mathrm{a}(\mathrm{T})$ is assumed to be that of the second virial coefficient.

- Carnahan-Starling-van der Waals-Soave (CSvdWS) EOS-a noncubic equation in which the repulsive term of the Carnahan-Starling equation [48] is combined with the attractive term of the van der Waals equation using the temperature dependence of the parameter a(T) given by Soave.

- Carnahan-Starling-Soave-Redlich-Kwong (CSSRK) EOS-a noncubic equation in which the repulsive term of the Carnahan-Starling equation [48] is combined with the attractive term of the Soave-Redlich-Kwong equation.

- Cubic Chain-Of-Rotators (CCOR) EOS [49,50]—a cubic equation in which a simplified cubic form of the Carnahan-Starling equation for a hard-sphere fluid and a contribution to pressure due to the rotational motion of a polyatomic molecule are combined in the repulsive term, and a simplified form of the Alder potential is assumed in the attractive term. The EOS has four parameters, a(T), b, c(T) and d, related to the critical compressibility factor, and a parameter, $\mathrm{C}^{\mathrm{R}}$, related to the degree of rotational freedom. The critical compressibility factor $\mathrm{z}_{\mathrm{c}}$ and $\mathrm{C}^{\mathrm{R}}$ are correlated in terms of the accentric factor, $\omega$.

Several pure component magnitudes were calculated in order to test the different EOS. It is well known the difficulty of most cubic equations to reproduce compressibility factors in the critical region, particularly the lower values of $\mathrm{z}$. In this region the CSSRK EOS represents a good improvement, while the overall prediction keeps reasonable accuracy. Figure 5 shows the experimental and calculated values of $\mathrm{N}_{2} \mathrm{O}$ compressibility factor, using the CSSRK EOS compared to the results using the SRK EOS.

Similarly, the CSSRK EOS is able to reproduce the saturation curve of $\mathrm{N}_{2} \mathrm{O}$ better that most common cubic EOS. Figure 6 shows the experimental and calculated values for $\mathrm{N}_{2} \mathrm{O}$ using using CSSRK and SRK EOS. For pure hydrocarbons, results obtained for the compressibility factor on the saturation curve, and for the enthalpy of vaporization, using the Carnahan-Starling modified equations, are similar to those obtained using other cubic EOS. 


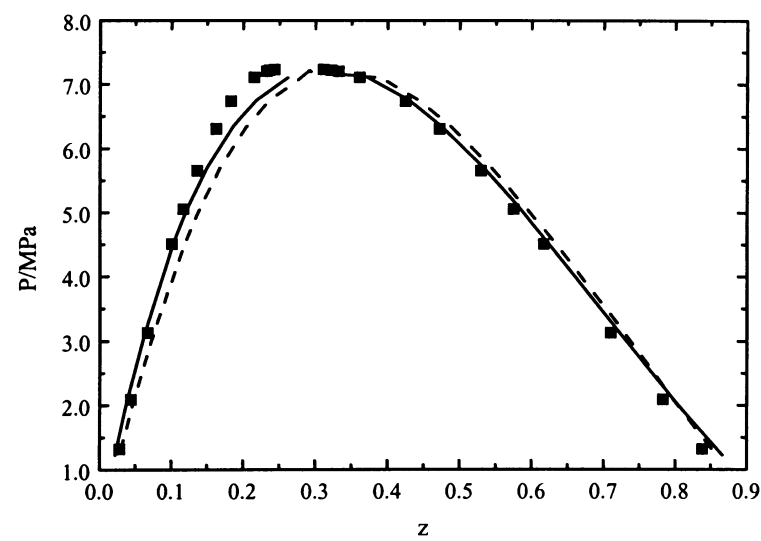

Fig. 6 Saturation curve for $\mathrm{N}_{2} \mathrm{O}: \mathbf{\square}$, experimental; - , calculated using CSSRK EOS; - - -, calculated using SRK EOS.

$\left[\mathrm{H}-\mathrm{H}^{*}\right]$ for the mixture is calculated using mixing rules for the EOS constants $\mathrm{a}, \mathrm{b}$, etc. These rules introduce binary interaction parameters which are usually determined from experimental binary data. Two different mixing rules are used to compare the ability of the different EOS to correlate excess enthalpies. The mixing rules used are the one-fluid van der Waals mixing rule or classical rule with two binary parameters, and the Wong-Sandler mixing rule [51] which has three binary interaction parameters. For a generic parameter $\theta$, which may represent $\mathrm{a}, \mathrm{b}, \mathrm{c}$ in a given $\mathrm{EOS}$, the classical mixing rule combines the pure-component parameters according to,

$\theta=\sum_{\mathrm{i}} \sum_{\mathrm{j}} \mathrm{x}_{\mathrm{i}} \mathrm{x}_{\mathrm{j}} \theta_{\mathrm{ij}}$

where $\theta_{\mathrm{ij}}$ is estimated either as,

$\theta_{\mathrm{ij}}=\left(\theta_{\mathrm{i}} \theta_{\mathrm{j}}\right)^{\frac{1}{2}}\left(1-\mathrm{k}_{\mathrm{ij}}\right) ; \quad \theta \equiv$ energetic parameter

or

$\theta_{\mathrm{ij}}=\frac{\left(\theta_{\mathrm{i}}+\theta_{\mathrm{j}}\right)}{2}\left(1-\delta_{\mathrm{ij}}\right) ; \quad \theta \equiv$ volumetric parameter and $\mathrm{C}^{\mathrm{R}}$

where $\mathrm{k}_{\mathrm{ij}}=\mathrm{k}_{\mathrm{ji}}$ and $\delta_{\mathrm{ij}}=\delta_{\mathrm{ji}}$ are the binary interaction parameters. For the PR, PRSV, SRK, PT, CSvdWS and CSSRK EOS two binary interaction parameters are used in the a and b expressions. For the Kubic and CCOR EOS, two interaction parameters are used in the a and $\mathrm{c}$ expressions.

The Wong-Sandler mixing rule defines the mixture parameters $a$ and $b$ as those which simultaneously satisfy the relations,

$\mathrm{b}-\frac{\mathrm{a}}{\mathrm{RT}}=\sum_{\mathrm{i}} \sum_{\mathrm{j}} \mathrm{x}_{\mathrm{i}} \cdot \mathrm{x}_{\mathrm{j}} \cdot\left[\mathrm{b}-\frac{\mathrm{a}}{\mathrm{RT}}\right]_{\mathrm{ij}}$

$\frac{\mathrm{G}^{\mathrm{E}}}{\mathrm{CRT}}=\frac{\mathrm{a}}{\mathrm{bRT}}-\sum_{\mathrm{i}} \mathrm{x}_{\mathrm{i}} \cdot \frac{\mathrm{a}_{\mathrm{i}}}{\mathrm{b}_{\mathrm{i}} \mathrm{RT}}\left[\frac{\mathrm{C}_{\mathrm{i}}}{\mathrm{C}}\right]$

where $\mathrm{C}$ and $\mathrm{C}_{\mathrm{i}}$ depend on the EOS used and $\mathrm{G}^{\mathrm{E}}$ is described by any of the vapor-liquid equilibrium models. In this paper, the Wilson model was adopted. The cross virial coefficient term appearing in eqn 6 , is calculated using eqn 5 , thus introducing one additional adjustable parameter. The number of binary parameters used in this procedure is three, two for the Wilson's model and one for the cross virial coefficient term. For the two-parameter PR, PRSV, and SRK EOS, C $=\mathrm{C}_{\mathrm{i}}$ is a numerical constant, characteristic of the cubic EOS. For the PT EOS, $C$ and $C_{i}$ are functions of the parameters $b$ and $c$, requiring an additional mixing rule for $\mathrm{c}$. Equations (3) and (5) were used for this purpose. 


\section{RESULTS AND CONCLUSIONS}

Results for the comparison between experimental values of $\mathrm{H}_{\mathrm{m}}^{\mathrm{E}}$ and those calculated using the different EOS are given in Tables 1 and 2. The binary interaction parameters were adjusted to give the best fit to the experimental $\mathrm{H}_{\mathrm{m}}^{\mathrm{E}}$ values at all the temperatures for which data are available. Table 1 lists results obtained for the eight EOS and the classical mixing rule. Values for the standard deviation between experimental and calculated excess enthalpies are similar for the PR, PRSV, SRK, and PT EOS. Deviations using these EOS are higher for $\mathrm{N}_{2} \mathrm{O}+$ pentane. This could have been expected since data for the $\mathrm{N}_{2} \mathrm{O}+$ pentane were taken at $(\mathrm{P}, \mathrm{T})$ conditions $(\mathrm{T}=308.15$ and $313.15 \mathrm{~K})$ closer to the $\mathrm{N}_{2} \mathrm{O}$ critical point than those of the other data. The CSSRK EOS has been shown to reproduce better the $\mathrm{N}_{2} \mathrm{O}$ properties near its critical point. The CSvdWS and CSSRK EOS lead to more accurate $\mathrm{H}_{\mathrm{m}}^{\mathrm{E}}$ values for $\mathrm{N}_{2} \mathrm{O}+$ pentane. However, this improvement is not general; it is observed for three of the systems studied: $\mathrm{N}_{2} \mathrm{O}+$ pentane, + heptane and + toluene. The Kubic EOS and, in most cases, the CCOR EOS lead to higher deviations than the other EOS.

Table 1 Standard deviations, $\sigma(\mathrm{J} / \mathrm{mol})$, between experimental $\mathrm{H}_{\mathrm{m}}^{\mathrm{E}}$ values and those calculated using several EOS and the classical combination rule with two binary interaction parameters

\begin{tabular}{lcccccccc}
$\begin{array}{l}\text { System } \\
\mathrm{N}_{2} \mathrm{O}+\end{array}$ & PR & PRSV & SRK & PT & Kubic & CSvdWS & CSSRK & CCOR \\
\hline pentane & 300 & 300 & 300 & 300 & 350 & 48 & 80 & 140 \\
hexane & 120 & 120 & 120 & 120 & 170 & 310 & 240 & 170 \\
heptane & 160 & 160 & 160 & 160 & 290 & 200 & 150 & 150 \\
octane & 140 & 140 & 140 & 140 & 240 & 360 & 290 & 260 \\
cyclohexane & 110 & 100 & 110 & 110 & 150 & 270 & 210 & 230 \\
toluene & 190 & 190 & 190 & 190 & 290 & 230 & 170 & 150 \\
\hline
\end{tabular}

Table 2 shows results obtained using the Wong-Sandler mixing rule and the EOS to which this rule may be applied. Deviations are substantially lowered with respect to those in Table 1 . This rule seems to confer more flexibility to the $\left[\mathrm{H}-\mathrm{H}^{*}\right]_{\text {mixture }}$ terms of eqn 1 . A comparison of deviations shown in Tables 1 and 2 indicates that a good correlation for $\mathrm{N}_{2} \mathrm{O}+$ pentane is only provided by the CSvdWS and CSSRK EOS. Several EOS may be used for the other systems.

Table 2 Standard deviations between experimental $\mathrm{H}_{\mathrm{m}}^{\mathrm{E}}$ values and those calculated using several EOS and the Wong-Sandler mixing rule

\begin{tabular}{lcccc}
\hline System & PR & PRSV & SRK & PT \\
$\mathrm{N}_{2} \mathrm{O}+$ & $\sigma(\mathrm{J} / \mathrm{mol})$ & $\sigma(\mathrm{J} / \mathrm{mol})$ & $\sigma(\mathrm{J} / \mathrm{mol})$ & $\sigma(\mathrm{J} / \mathrm{mol})$ \\
\hline pentane & 170 & 170 & 180 & 180 \\
hexane & 90 & 89 & 84 & 82 \\
heptane & 82 & 81 & 78 & 78 \\
octane & 140 & 140 & 130 & 120 \\
cyclohexane & 89 & 89 & 92 & 90 \\
toluene & 170 & 170 & 170 & 170 \\
& & & & \\
\hline
\end{tabular}

\section{ACKNOWLEDGEMENTS}

We appreciate the aid given to us in estimating the critical locus by Dr R. A. Heidemann. This work was funded by the Spanish Ministery of Education, PB-97-0315. A.C. wishes to acknowledge the University Complutense for its support through a Predoctoral grant.

\section{REFERENCES}

1 C. J. Wormald, K. L. Lewis, S. E. Mosedale. J. Chem. Thermodynamics 9, 27-42 (1977).

2 K. L. Lewis, S. E. Mosedale, C. J. Wormald. J. Chem. Thermodynamics 9, 121-131 (1977). 
3 C. J. Wormald, L. Badock, M. J. Lloyd. J. Chem. Thermodynamics 28, 603-613 (1996).

4 J. J. Christensen, L. D. Hansen, D. J. Eatough, R. M. Izatt, R. M. Hart. Rev. Sci. Instrum. 47, 730-734 (1976).

5 J. J. Christensen, L. D. Hansen, R. M. Izatt, D. J. Eatough, R. M. Hart. Rev. Sci. Instrum. 52, 1226-1231 (1981).

6 C. Pando, J. A. R. Renuncio, R. M. Izatt. J. J. Christensen. J. Chem. Thermodynamics 15, 231-240 (1983).

7 C. Pando, J. A. R. Renuncio. T. A. Mcfall, R. M. Izatt, J. J. Christensen. J. Chem. Thermodynamics 15, 259-266 (1983).

8 J. J. Christensen, P. W. Faux, D. R. Cordray, R. M. Izatt. J. Chem. Thermodynamics 18, 1053-1064 (1986).

9 J. J. Christensen, T. A. C. Walker, R. S. Schofield, P. W. Faux, P. R. Harding, R. M. Izatt. J. Chem. Thermodynamics 16, 445-451 (1984).

10 J. J. Christensen, D. M. Zebolsky, R. M. Izatt. J. Chem. Thermodynamics 17, 183-192 (1985).

11 J. J. Christensen, S. P. Christensen, R. S. Schofield, P. W. Faux, P. R. Harding, R. M. Izatt. Thermochim. Acta 67, 315-325 (1983).

12 J. J. Christensen, S. P. Christensen, R. S. Schofield, P. W. Faux, P. R. Harding, R. M. Izatt. J. Chem. Thermodynamics 15, 1151-1157 (1983).

13 J. J. Christensen, T. A. C. Walker, D. R. Cordray, R. M. Izatt. J. Chem. Thermodynamics 19, 47-56 (1987).

14 D. R. Cordray, R. M. Izatt, J. J. Christensen, J. Chem. Thermodynamics 20, 225-234 (1988).

15 C. Pando, J. A. R. Renuncio, T. A. McFall, R. M. Izatt, J. J. Christensen. J. Chem. Thermodynamics 15, 173-180 (1983).

16 J. J. Christensen, D. R. Cordray, R. M. Izatt. J. Chem. Thermodynamics 18, 53-61 (1986).

17 C. Pando, J. A. R. Renuncio, R. S. Schofield, R. M. Izatt, J. J. Christensen. J. Chem. Thermodynamics 15, 747-755 (1983).

18 J. J. Christensen, D. M. Zebolsky, R. M. Izatt. J. Chem. Thermodynamics 17, 1-10 (1985).

19 D. R. Cordray, J. J. Christensen, R. M. Izatt. J. Chem. Thermodynamics 18, 647-656 (1986).

20 D. R. Cordray, J. J. Christensen, R. M. Izatt, J. L. Oscarson. J. Chem. Thermodynamics 20, 877-888 (1988).

21 J. J. Christensen, S. P. Christensen, R. S. Schofield, P. W. Faux, P. R. Harding, R. M. Izatt. J. Chem. Thermodynamics 16, 249-255 (1984).

22 J. J. Christensen, D. M. Zebolsky, R. M. Izatt. J. Chem. Thermodynamics 17, 785-795 (1985).

23 R. M. Izatt, S. E. Gillespie, J. L. Oscarson, P. Wang, J. A. R. Renuncio, C. Pando. J. Solution Chem. 23, 449-468 (1994).

24 R. M. Izatt, J. L. Oscarson, S. E. Gillespie, H. Grimsrud, J. A. R. Renuncio, C. Pando. Biophys. J. 61, 1394-1401 (1992).

25 S. E. Gillespie, J. L. Oscarson, R. M. Izatt, P. Wang, J. A. R. Renuncio, C. Pando. J. Solution Chem. 24, 1221-1249 (1995).

26 J. B. Ott, C. J. Wormald. Excess Enthalpy by Flow Calorimetry. In: Experimental Thermodynamics, Vol. VI. Solution Thermodynamics (K. N. Marsh, P. A. G. O'Hare, eds). Blackwell, London (1994).

27 C. Mathonat, V. Hynek, V. Majer, J. P. E. Grolier. J. Solution Chem. 23, 1161-1182 (1994).

28 ICTAC, Thermochemistry Working Group. In Reference materials for calorimetry and differential thermal analysis (R. Sabbah, ed.). Thermochim. Acta 331, 179-180 (1999).

29 N. Alexandrou, M. J. Lawrence, J. Pawliszyn. J. Anal. Chem. 64, 301-311 (1992).

30 U. Haarhaus, P. Swidersky, G. M. Schneider. J. Supercrit. Fluids 8, 100-106 (1995).

31 P. Subra, S. Castellani, H. Ksibi, Y. Garrabos. Fluid Phase Equil. 131, 269-286 (1997).

32 R. E. Sievers, P. Hansen. Chem. Eng. News 69, 2-106 (1991).

33 R. A. Heidemann, A. M. Khalil. AIChE J. 26, 769-779 (1980).

34 R. C. Castells, C. Menduiña, C. Pando, J. A. R. Renuncio. J. Chem. Thermodynamics 26, 641-646 (1994).

35 R. C. Castells, C. Menduiña, C. Pando, J. A. R. Renuncio. J. Chem. Soc. Faraday Trans. 90, 2677-2681 (1994).

36 J. A. R. Renuncio, C. Pando, C. Menduiña, R. C. Castells. J. Chem. Eng. Data 40, $642-644$ (1995).

37 A. Cabañas, C. Pando, C. Menduiña, J. A. R. Renuncio. J. Supercrit. Fluids 10, 75-86 (1997).

38 A. Cabañas, B. Pittau, C. Pando, J. A. R. Renuncio. J. Chem. Soc. Faraday Trans. 93, 3067-3071 (1997). 
39 B. Pittau, A. Cabañas, C. Pando, J. A. R. Renuncio. Ber. Bunsenges. Phys. Chem. 102, 7-13 (1998).

40 A. Cabañas, C. Menduiña, C. Pando, J. A. R. Renuncio. Ind. Eng. Chem. Res. 37, 3036-3042 (1998).

41 E. J. Couch, L. J. Hirth, K. A. Kobe. J. Chem. Eng. Data 6, 229-237 (1962).

42 D.-Y. Peng, D. B. Robinson. Ind. Eng. Chem. Fundam. 15, 59-64 (1976).

43 R. Stryjek, J. H. Vera. Can. J. Chem. Eng. 64, 323-333 (1986).

44 R. Stryjek, J. H. Vera. Can. J. Chem. Eng. 64, 334-340 (1986).

45 G. Soave. Chem. Eng. Sci. 27, 1197-1203 (1972).

46 N. C. Patel, A. S. Teja. Chem. Eng. Sci. 37, 463-473 (1982).

47 W. L. Kubic. Fluid Phase Equil. 9, 79-97 (1982).

48 N. F. Carnahan, K. E. Starling. AIChE J. 18, 1184-1189 (1972).

49 H. M. Lin, H. Kim, T. M. Guo, K. C. Chao. Fluid Phase Equil. 13, 143-152 (1983).

50 H. Kim, H. M. Lin, K. C. Chao. Ind. Eng. Chem. Fundam. 25, 75-84 (1986).

51 D. S. Wong, S. I. Sandler. AIChE J. 38, 671-680 (1992). 